\title{
The Application of VR Technologies in the Practice of Innovation and Entrepreneurship in Colleges and Universities
}

\author{
Zhi-wang DING ${ }^{1, a}$, Hong-juan $\mathrm{LI}^{2, \mathrm{~b}}$, Zhen-yu HU $\mathrm{H}^{3, \mathrm{c}^{*}}$ \\ ${ }^{1,3}$ Student Affairs Office, Jiangxi University of Traditional Chinese Medicine, Nanchang, Jiangxi, China \\ ${ }^{2}$ International Education College, Jiangxi University of Traditional Chinese Medicine, Nanchang, Jiangxi, China \\ a80522024@qq.com, b249556449@qq.com, ${ }^{\mathrm{c}} 491673015 @ q q . c o m$ \\ *Corresponding author
}

\begin{abstract}
This paper combines popular VR technologies and college innovation and entrepreneurship. Starting from the characteristics of VR technologies, it elaborates on the three advantages of innovation and entrepreneurship skills training, education, and practice in colleges and universities. Based on the analysis of six outstanding problems in the application of VR technologies in colleges and universities' innovation and entrepreneurship practices, supported by funds, this paper proposes solutions including course optimization, environmental construction.
\end{abstract}

Keywords-VR technologies; Colleges; Innovation and entrepreneurship

\section{INTRODUCTION}

Translating Virtual Reality into Chinese is a virtual reality technology. It is a technology that simulates real scenes through computer technology, breaks through illusions, and allows people to have a real feeling and use awareness to perceive reality. As a cutting-edge technology, it has attracted much attention in the international community today. Currently, it plays an increasingly important role in scientific computing visualization, design and planning, commerce, medicine, education and many other fields. VR technology has the following three basic characteristics:

\section{A. Immersiveness}

"To be in a non-invasive environment, evil can be poor in its side cliffs, referring to their homes." This sentence is the source of the term immersive. VR technology allows the experiencer to feel the reality in the virtual reality. Its main working principle is to construct a virtual reality system. The virtual reality system is also called a virtual reality platform. This is a high-tech field in the field of graphics and graphics that has emerged in recent years. It is also called spiritual technology or artificial environment. Virtual reality is the use of computer simulations to create three-dimensional virtual worlds, providing users with visual, auditory, and tactile sensory simulations, allowing users to feel themselves in the real world and be able to observe anything in threedimensional space.

\section{B. Interaction}

Refers to the user's degree of operability in a simulated environment and the level of natural feedback from the environment (including real-time). Users can master virtual objects directly in the simulation environment. At this point, the hand has the feeling of holding the object and can feel the weight of the object. The captured object in the field of view can also move immediately as the hand moves. Interactions, literally mean mutual communication. In virtual reality, the experiencer can manipulate the objects in the virtual environment. For example, the experiencer can pick up guns, knives, swords, and other weapons in a virtual environment and can use weapons.

\section{Construction}

VR technology can not only reproduce the real scene, but also can imagine things that do not exist objectively, and even construct an environment that does not exist in reality, which can inspire people's imagination. For example, in the current movie, we can see many non-existent things and scenes built using VR technology. Virtual reality technology has a vast imaginable space, which can broaden the scope of human cognition. It not only replicates the real environment, but also freely conceives an environment that is objectively absent or even impossible.

\section{THE CONCEPT OF INNOVATION AND ENTREPRENEURSHIP}

Innovation, that is, the creation of new things, refers to the use of existing thinking patterns to bring forward insights that are different from conventional or ordinary ideas, use existing knowledge and materials, improve in line with idealized needs, or satisfy social needs. Or create new things, methods, and get some beneficial effects. Innovation and entrepreneurship refer to entrepreneurial activities based on technological innovation, product innovation, brand innovation, service innovation, business model innovation, management innovation, organizational innovation, market innovation, and channel innovation. Innovation and entrepreneurship are the focus of the current society. Innovation is the specialty of innovation and entrepreneurship. Entrepreneurship is the goal of 
innovation and entrepreneurship. Premier Li Keqiang explicitly stated in the "2015 Central Government Work Report" that "mass entrepreneurship and innovation" is one of the "twin engines" that promote China's economic upgrading and efficiency upgrading.

Undergraduates have received a professional, systematic, and scientific university education. They have professional skills and excellent comprehensive qualities. They have an active mind, a strong ability to accept new things, and have the potential for innovation. They have become a main force for innovation and entrepreneurship. University students' innovation and entrepreneurship can effectively relieve employment pressure, promote the construction of an innovative country in our country, and adapt to the development of the market economy environment. Cultivating the ability and quality of college students' innovation and entrepreneurship has important practical significance.

\section{THE ADVANTAGES OF VR TECHNOLOGY IN THE PRACTICE OF INNOVATION AND ENTREPRENEURSHIP IN COLLEGES AND UNIVERSITIES}

\section{A. VR technology applied to innovation and entrepreneurial skills training}

Any skill must be practiced continuously before it can be truly mastered. For example, traditional medical teaching methods and teaching models are often completed in the form of teaching examples, teaching models, experimental animals, autopsy, and on-site observations. In contrast, the virtual environment built by VR technology not only can be repeatedly trained but also has high security. In the Internet age, medical education should also catch up with the trend of the times. Multi-mode teaching and multi-teaching methods should become the mainstream of medical education. Medical students can only use expensive and difficult-to-buy corpses in traditional surgical training. The corpse should be kept for 2-3 weeks, and it should be stored for a long time. It is also a dozen or more than 20 people sharing a corpse for experiments. Students can hardly really learn anything. The VR technology not only saves resources, but also enables students to better use this technology in all aspects of innovation and entrepreneurship through a realistic virtual experiment environment. The foundation of technology is the cornerstone of practice. College students can only apply their skills in the innovation and entrepreneurial practice only if they have a solid grasp of the skills they have learned. The significance and application of VR technology in skills training will also inevitably affect innovation and entrepreneurship practices, thus making practice activities more and more smooth.

\section{B. VR technology applied to innovation and entrepreneurship education}

VR technology is currently widely used in many fields, and its applications in military, entertainment, industrial manufacturing, aerospace, and medicine are very representative. Life is alive. What if there is no other thing in life? Therefore, the application of VR technology in the medical field has particularly important practical value. For example: In the field of cognitive rehabilitation, VR technology has a very important application. More and more research shows that VR technology has extensive applications in cognitive rehabilitation such as spatial cognitive impairment, attention disorder, thinking disorder, memory impairment, life skills cognitive impairment, and in the treatment of neuropsychological aspects. Also achieved good results.

\section{Online Experience of Consumers Using VR Technology in Innovation and Entrepreneurship}

The online experience of VR technology helps to realize the collection of big data for users' consumption trends, enabling suppliers to grasp consumer demand. With the maturity of VR technology, more and more online VR experience platforms and websites will be more complete, students can simulate, potential customers use these platforms to select their favorite products, and big data analysis systems can collect consumers more efficiently. Browse information to analyze consumer trends and keep up with consumer trends. Sales can also be transformed from the traditional "what designers design, what suppliers produce, what consumers buy" model to "what consumers like and what suppliers produce.

\section{THE VR TECHNOLOGY'S PROBLEMS IN COLLEGES AND UNIVERSITIES IN INNOVATION AND ENTREPRENEURSHIP}

\section{A. Lack of innovative technology and less patents}

At present, college students have high entrepreneurial enthusiasm. Countries and colleges and universities have more investment in VR technology in terms of hardware and policy preferences. However, technologies such as image technology and data still face many technical bottlenecks. Most of the technical research is borrowed from abroad. VR technology, or modify its code, lacks its own proprietary technology.

\section{B. Lack of VR content, resulting in the non-sticky users}

Since VR content creation requires a large amount of rendering to achieve immersive effects, the time and effort spent on production is dozens of times that of traditional content production. Therefore, many VR contents still remain in the demo and concept stages. Few hardware are willing to burn money on content, and think that it also makes the user experience poor. In addition, VR applications are still focused on video, games, and other content is relatively small, resulting in the user is not sticky. Coupled with the fact that the industry is still in the early stage of seed user development, the lack of a user base has prevented the team from making a profit. 


\section{The cost of VR equipment is high and it is hard to reach people's lives}

As an emerging product, immersing VR devices that are currently able to bring better immersiveness to users are relatively high in price, resulting in a slow adoption rate in the market. However, some domestic VR products with lower prices are easy to be hampered and easily homogenized. The user experience is poor.

\section{VR hardware manufacturers standards are not uniform}

At present, VR hardware manufacturers have reached a unified standard, so there has been a hundred contending situation, every hardware manufacturer is trying to build their own ecosystem, such as HTC Vive has a Steam platform, Oculus has an Oculus Store, the consequences of this situation is the downstream Content production vendors can only selectively develop. Due to the incompatibility of upstream hardware vendors' equipment, including different communication protocol standards, the input and output devices are not uniform, and the same content needs to bB. adapted to different hardware. Different from redevelopment. Considering the commercial cost and the sustainable development of the industry, the standardization of VR equipment will be imperative. VR social networking is one of the most complex VR applications. It can bring people from any corner of the world together, but unlike today's flat Internet social networks, it has only voice, text, pictures, and video content. It also has virtual 3D entities. The construction is therefore more real, and the core of this goal is the Internet of VR. Different from VR's local or local area network applications, connecting VR devices around the world through the Internet requires not only a unified communication protocol standard, but also The hardware device performance also puts forward higher requirements.

\section{E. There is a lack of funding during the start-up phase.}

There is a large gap in the domestic Internet market for entrepreneurs to explore. It is undoubted that there will be good business prospects for undergraduates to engage in Internet entrepreneurship. However, Internet entrepreneurship requires a lot of capital investment, but the economic source of undergraduate students mainly depends on their parents. Families with better conditions can afford the funds needed for the entrepreneurial process, and for families with average economic conditions, they can't afford to bear the huge costs of the initial stage of the venture. The entrepreneurial market can change at any time, and it is impossible to estimate the operating conditions. Caused some students to give up business.

\section{F. Lack of a good entrepreneurial environment.}

Our country pays more and more attention to college students' entrepreneurial work. However, compared with developed countries, the entrepreneurial environment in China is generally at the mid-lower level. Entrepreneurs have more complex procedures in the process of entrepreneurship. First of all, although students in school have financial support but need to be reviewed by the administrative department of the university, they can get financial help after the approval of various departments, and less funds can hardly make up for the financial losses in the early stage of the venture. Second, the Internet as a new start-up business does not yet have more mature entrepreneurial experience.

\section{SOLUTION TO THE Problem OF MAKING USE OF VR TECHNOLOGY IN INNOVATION AND ENTREPRENEURSHIP IN COLLEGES AND UNIVERSITIES}

\section{A.Increase policy and financial support.}

Although the state has introduced a series of preferential policies for college students in innovation and entrepreneurship, the support for funding is still insufficient. Therefore, colleges and universities should increase their efforts to encourage college students to start their own businesses, increase their financial support for entrepreneurial ventures, provide their students with free office space, and establish entrepreneurial funds, creating a good environment for their business.

B.adjust the curriculum structure. Entrepreneurship is a difficult process. Many students are afraid of delaying their studies in this process. Therefore, colleges and universities should make adjustments to the curriculum arrangements for the students who start their own businesses.

C.to create a good business environment. For college students to start a business, the state will provide guidance for them free of charge. This form is only limited in theory and cannot be compared with the real business environment. Therefore, colleges and universities need to increase the proportion of entrepreneurship courses in the curriculum and allow students to contact the business environment as soon as possible. For students with entrepreneurial ideas, ask some professional instructors, social celebrities to guide, face to face communication, to ensure that in the actual environment can play a better role. 


\section{CONCLUSION}

With the full development of computer technology, VR technology has become the "new darling of education innovation." With VR technology and resources constantly maturing and expanding, VR technology and resources will be widely used in various fields of education and teaching. In the practice of innovation and entrepreneurship in colleges and universities, students in colleges and universities should learn to use VR technology rationally. In particular, students in innovation and entrepreneurship need to master this technology. Through the use of VR technology, independent intellectual property rights and other innovative perspectives, aiming at different innovation and entrepreneurial projects, build a corresponding virtual laboratory, so that students can acquire skills in continuous training, in order to have sufficient strength to occupy the international VR market competition. A place, and then realize the transformation of China's manufacturing power to a technological power.

\section{REFERENCES}

[1] Tan Qian, Tan Daxi. The practice and research of maker education based on 3D printing technology [J]. Business Managers, 2016(34):481.

[2] Zhao Xiaoying, Liu Ping. The project teaching method based on 3D printing in the cultivation of "customers"The application of [J]. Academic Weekly, 2016 (34): 230-231.

[3] Ma Chongyu, Chen Jianlin. Computer-assisted language teaching based on virtual reality - theory,Methods and techniques []]. Foreign language teaching, 2012, (06): 28 -33.

[4] Zhang Zhibiao. Application of Virtual Reality Education: Education for Pursuing Body and Mind - From Beijing TeachersA Talk on "Wisdom Learning and V R Education Application Week" at Fan University [J].China Distance Education Yu, 2016,(06):5 -15. 